\title{
REFORMA TRABALHISTA E A MUDANÇA DE PARADIGMA DO NEGOCIADO SOBRE O LEGISLADO
}

\author{
Walkiria Martinez Heinrich Ferrer* \\ Lourival José de Oliveira**
}

SUMÁRIO: Introdução; 2 A modernização das relações de trabalbo; $3 \mathrm{~A}$ regulamentação da legislação trabalbista: a Lei 14.467/2017 e a MP 808/2017; 4 A flexibilização nas relações contratuais: o negociado sobre o legislado; $5 \mathrm{~A}$ fragilidade do processo de negociação coletiva; 6 Considerações finais; Referências.

RESUMO: Seguindo a tendência de reestruturação do processo produtivo em termos mundiais, no mundo do trabalho as transformações produtivas justificaram em parte a necessidade de adequação da legislação trabalhista às novas condições de mercado, promovendo assim a flexibilização da normatização das relações de trabalho. Especificamente, no Brasil, a flexibilização nas relações trabalhistas foi objetivada pela reforma trabalhista, em vigor desde novembro de 2017. Por meio do método dedutivo e análise documental, o presente estudo demonstrou a mudança de paradigma adotado pela Reforma Trabalhista que foi promovida através da lei $\mathrm{n}^{\mathrm{o}} 13.467$, de 17 de julho de 2017, em especial no que se refere aos acordos e às convenções coletivas de trabalho, que conflitaram com os principais vetores constitucionais, dentre os quais o valor trabalho humano, que se constitui um dos fundamentos da República, com a finalidade de propiciar a redução da desigualdade social por meio do trabalho.

PALAVRAS-CHAVE: Flexibilização; Negociação nas relações de trabalho; Reforma trabalhista.

\section{THE LABOR REFORM AND PARADIGM CHANGES ON WHAT IS AGREED UPON WITH REGARD TO THE LAW}

ABSTRACT: Following the trend for the restructuring of the production process worldwide, production transformations within the labor milieu have partially

\footnotetext{
"Docente do Programa de graduação, mestrado e doutorado da Universidade de Marília, São Paulo. Doutorado e Mestrado em Educação pela UNESP/Marília. Líder do grupo de pesquisa Globalização, soberania e neoliberalismo, inscrito regularmente no DGP/CNPq. Pós-doutoranda em Sociologia do Trabalho pela UNESP/ Marília (SP) Brasil. E-mail: walkiriamf@terra.com.br

* Docente titular do Programa de graduação, mestrado e doutorado da Universidade de Marília, Marília (SP). Doutor em Direito das Relações Sociais (PUC-SP); Docente Associado C da Universidade Estadual de Londrina (UEL), Brasil.
} 
justified the need for adapting labor laws to the new market conditions. The flexibilization of labor relationships is thus enforced. The flexibilization of labor relationships was triggered by the 2017 labor reform. Current analysis, based on deduction and document analysis, shows the paradigm changes adopted by the Labor Reform through Law 13,467, issued on July 17, 2017, with regard to agreements and collective labor conventions that conflicted with the main constitutional vectors. The value of human labor is one of the basic items in the republican constitution to reduce social inequality through labor.

KEY WORDS: Flexibilization; Agreement on labor relationships; Labor reform.

\section{REFORMA LABORAL Y EL CAMBIO DE PARADIGMA DEL NEGOCIADO SOBRE EL LEGISLADO}

RESUMEN: Siguiendo la tendencia de reestructuración del proceso productivo en términos mundiales, en el mundo del trabajo las transformaciones productivas justificaron en parte la necesidad de adecuación de la legislación laboral a las nuevas condiciones de mercado, promoviendo así la flexibilización de la normalización de las relaciones de trabajo. Específicamente, en Brasil, la flexibilización en las relaciones laborales fue objetivada por la reforma laboral, en vigor desde noviembre de 2017. Por intermedio del método deductivo y análisis documental, en el presente estudio se demostró el cambio de paradigma adoptado por la Reforma Laboral que fue promovida por intermedio de la Ley $\mathrm{n}^{0} 13.467$, de 17 de julio de 2017, en especial en lo que se refiere a los acuerdos y a las convenciones colectivas de trabajo, que conflictuaron con los principales vectores constitucionales, entre los cuales el valor trabajo humano, que se constituye uno de los fundamentos de la República, con la finalidad de propiciar la reducción de la desigualdad social por intermedio del trabajo.

PALABRAS CLAVE: Flexibilización; Negociación en las relaciones laborales; Reforma laboral.

\section{INTRODUÇÃO}

As décadas de 1970 e 1980 foram marcadas por profundas transformações no cenário político, econômico e social em termos mundiais. No contexto da nova ordem mundial as instituições tornaram-se adaptáveis aos novos tempos. E essa adaptabilidade, verificada em diferentes setores, acaba se tornando causadora de uma infinidade de retrocessos nos direitos sociais, além de potencializar a exclusão de parcelas significativas da população mundial. 
Como resposta às novas condições de produção, adaptação ao contexto da ordem mundial e atendendo ao discurso da modernização das instituições, as questões trabalhistas também sofreram transformações, que se manifestaram especialmente nas relações de trabalho, com a expropriação dos direitos assegurados ao trabalhador e consequente precarização do trabalho. Especificamente no Brasil a reforma trabalhista, em vigor desde novembro de 2017 por meio da lei $\mathrm{n}^{0} 13.467$, objetivou a pretensa modernidade, gerando alterações em direitos assegurados por décadas de mobilização dos trabalhadores.

Sob o discurso da necessidade imediata da modernização das relações trabalhistas, perante o quadro de reestruturação produtiva da ordem econômica mundial, a reforma trabalhista surge como discurso apto a, supostamente, promover o crescimento do país e reverter o contexto de crise/recessão econômica.

Assim que, em nome dessa pretensa modernidade nas relações de trabalho, se expropria o trabalhador até mesmo de direitos e garantias consagrados pela Constituição Federal. As normas emanadas da legislação federal destinam-se à satisfação e à garantia dos direitos dos trabalhadores, contribuindo para a efetivação de seu valor social, colocando-o como instrumento de concretização da dignidade da pessoa humana.

Hoje, a visualização de onde estejam os direitos dos trabalhadores na 'geografia' constitucional é bastante clara: o Título II da Constituição de 1988 trata 'Dos Direitos e Garantias Fundamentais'. Dentro deste título está o capítulo II, denominado 'Dos Direitos Sociais'.

$[\ldots]$

Quis o constituinte demonstrar que os direitos trabalhistas têm grande importância, razão pela qual, diferentemente do que ocorria nas outras ordens constitucionais, foram colocados no início da nova Carta, em local de destaque. ${ }^{03}$

Por ser o trabalho mais do que o instrumento de garantia de sobrevivência do trabalhador, responsável pela manutenção de condições dignas de saúde, educação, moradia, deve ser preservado e protegido pela legislação trabalhista. Também, é por meio do trabalho que no meio de produção capitalista o trabalhador se externaliza

\footnotetext{
${ }^{03}$ MORAES, Camila Miranda de; GAIA, Fausto Siqueira. Reforma trabalhista e o conceito de sistema jurídico. Revista Jurídica Cesumar janeiro/abril 2018, v. 18, n. 1, p. 35-64, p. 51. Disponível em http://periodicos. unicesumar.edu.br/index.php/revjuridica/article/view/6212/3178. Acesso em 09 de julho 2018.
} 
socialmente, ou seja, se revela socialmente. Silva e Vergara (2002, p. 3-4), em seus estudos, falam a respeito da construção de uma identidade social a partir das interações entre os indivíduos e suas participações nos seus grupos sociais. Não é difícil perceber que as identidades individuais estarão sendo construídas a partir de e em conjunto com as identidades organizacionais, quer dizer, a partir da própria realidade laboral.

Considerando as justificativas apresentadas, o presente estudo tem como objetivos demonstrar a possível mudança de paradigma adotado pela reforma trabalhista promovida por meio da lei $n^{0} 13.467$, de 17 de julho de 2017, como também a alteração normativa nos seus principais pontos, levando-se em conta os vetores constitucionais, dentre os quais o valor trabalho humano como um dos fundamentos da República e as finalidades presentes no mesmo texto constitucional, destacando-se aqui a redução da desigualdade social por meio do trabalho.

\section{A MODERNIZAÇÃO DAS RELAÇÕES DE TRABALHO ${ }^{04 *}$}

O final do século XX certamente foi o cenário de profundas transformações, tanto na esfera política quanto econômica, cultural e social. O mundo tornou-se pequeno, as economias intensificaram o embricamento das relações comerciais, o custo social foi acentuado, aumentando consideravelmente a parcela dos excluídos. Mas por se tratar de um processo relativamente recente as consequências ainda não são conhecidas em sua totalidade. Mas há um ponto inquestionável e essas transformações foram desencadeadas, principalmente, pelas inovações tecnológicas.

$\mathrm{Na}$ sociedade contemporânea o domínio dos novos instrumentos gerados pela evolução tecnológica representa um meio concreto de interferência na gestão social, destacando-se ainda como um dos principais instrumentos de transformação e disseminação do conhecimento.

A reestruturação produtiva, gerada pelas transformações do capital na era globalizada, somada aos avanços tecnológicas em diferentes partes do processo produtivo, foi responsável por uma crescente demanda de inovações também nas relações de trabalho, alterando substancialmente sua concepção jurídica.

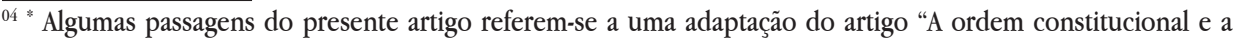
legislação trabalhista: algumas considerações" publicado nos Anais do XI Seminário do Trabalho. Acesso em 09 de junho de 2018. Disponível em http://www.canal6.com.br/xi_sem2018/gt_precarizacao.html
} 
Esta determinação de desregulamentação não se manifesta apenas no plano econômico, mas também no mundo do trabalho coma flexibilização das relações trabalhistas, o que significa uma oposição ao protecionismo estatal nas questões trabalhistas. Segundo o ideário neoliberal a livre negociação entre patrões e empregadores traria benefícios não somente aos trabalhadores, pois teriam maior liberdade de escolha, mas, principalmente, ao processo de reprodução e acumulação do capital, que teria maior liberdade nas relações contratuais. ${ }^{05}$

No polêmico contexto das reformas políticas e econômicas, encontra-se a reforma trabalhista, em vigência no país desde novembro de 2017. Se por um lado foi vista como um meio de promover ou até mesmo intensificar a precarização das condições de trabalho no Brasil, por outro lado poderia representar possibilidades de modernização das relações trabalhistas, visando sua adequação às novas condições do setor produtivo, advindas das transformações tecnológicas.

Embora o período de discussão da reforma das relações de trabalho no Brasil tenha sido quase que inexistente, foi o suficiente para promover diferentes concepções e entendimentos sobre a questão. No que diz respeito ao viés empresarial, é possível fundamentar sua concepção por meio das afirmações contidas em um documento da Confederação Nacional da Indústria - CNI intitulado "101 propostas para a modernização trabalhista", em que fica clara a necessidade da adequação da legislação trabalhista às necessidades do processo produtivo, ou, melhor dizendo, dos interesses da indústria.

A análise do documento permite observar o entendimento de que a legislação existente (Consolidação das Leis do Trabalho - CLT) trata o trabalhador de todo tipo como hipossuficiente, ou seja, a parte considerada frágil na relação capital trabalho, pois "[...] foi concebida em um momento histórico marcado pelo predomínio do trabalho na agricultura, por um processo de industrialização ainda incipiente, com trabalhadores ainda com reduzido nível de formação e qualificação e por um movimento sindical pouco estruturado". ${ }^{6}$

Segundo essa interpretação, a nova realidade gerada pela reestruturação

\footnotetext{
${ }^{05}$ FERRER, W.M.H.; ROSSINHOLI, M. Constituição Federal e direitos sociais: uma análise econômica e social do atual estado brasileiro. Revista Argumentum. Marília/SP, V. 19, N. 1, pp. 27-50, Jan.-Abr. 2018, p. 38. Acesso em 09 de julho de 2018. Disponível http://ojs.unimar.br/index.php/revistaargumentum/article/view/557.

${ }^{06}$ CONSELHO NACIONAL DA INDUSTRIA - CNI. 101 Propostas para a Modernização Trabalbista. Brasília, 2012. Disponível em http://bucket-gw-cni-static-cms-si.s3.amazonaws.com/legacy/app/ conteudo_18/2012/12/04/2728/20121204160144687771i.pdf. Acesso em fev. 2018, p. 16.
} 
produtiva do capital requer uma legislação menos rígida, que seja possível flexibilizar a condição do trabalhador como hipossuficiente e do empregador como hipersuficiente, visto que na atualidade coexistem diferentes tipos de trabalhadores e diferentes tipos de empregadores, mas uma legislação que padroniza ambos.

Ocorre que, ainda que se construa um fundamento capaz de justificar a reforma trabalhista ocorrida no Brasil (2017), vale a pena citar que outras economias passaram por crises de desemprego bastante semelhantes e que não adotaram uma mudança repentina como a brasileira e com o mesmo grau de ruptura em se tratando de direitos sociais.

Para se ter um exemplo, na Europa, ocorreram várias reformas trabalhistas, onde algumas podem até ser comparadas com a brasileira, sem, contudo, contar com o mesmo grau de aprofundamento. Podem ser citadas, como exemplo, a reforma ocorrida na França em 2016, que teve seu marco na mudança da jornada de trabalho, passando a permitir jornadas semanais de até 48 horas, com pagamento de horas extras. Também, a facilitação das demissões por motivos econômicos ou ainda a redução dos valores das rescisões contratuais para aqueles trabalhadores com mais de 20 anos de tempo de serviço na mesma empresa.

$\mathrm{Na}$ Alemanha, a reforma trabalhista foi feita em fases, na sua maioria negociada com os sindicatos. Pelo denominado plano Hartz, iniciado em 2003, dividiu-se em várias etapas a reforma trabalhista, acompanhando o desenvolvimento econômico. Na verdade, foram mudanças que alcançaram desde os planos de saúde, passando pela previdência social e chegando aos contratos temporários, com os mesmos direitos que os empregados denominados de permanentes.

Centrais sindicais, parte do corpo de magistrados, segmentos da sociedade civil e estudiosos analisam a restruturação das relações trabalhistas no Brasil como um evidente retrocesso em termos de direitos e garantias trabalhistas, duramente conquistados ao longo de décadas. Nesse sentido, fica a constatação de que a reforma trabalhista implementada de maneira afoita e intempestiva se mostrou em boa parte contrária aos princípios constitucionais, em especial os que estabelecem parâmetros para a ordem econômica, conforme disposto no artigo 170 da Constituição Federal

Considerada retrógrada, a reforma trabalhista feita com menos de um ano, seja do ponto de vista dos princípios constitucionais ou mesmo dos padróes internacionais de proteção ao trabalho, tem se mostrado incapaz de atender a um mínimo de proteção ao trabalho, irradiando os seus efeitos perversos para a 
economia e a própria sociologia. A reforma trabalhista ora empreendida reflete os mecanismos de perpetuação das desigualdades sociais, manifestando claramente objetivos com vistas à reprodução e manutenção da precariedade das relações de trabalho no Brasil. Além de um desacordo latente com os princípios constitucionais que asseguram as condições de valorização do trabalho.

\section{A REGULAMENTAÇÃO DA LEGISLAÇÃO TRABALHISTA: A LEI 14.467/2017 E A MP 808/2017}

A tramitação da reforma trabalhista não adveio de um processo longo de discussões entre a sociedade civil e os setores comprometidos com a garantia dos direitos trabalhistas, mas resultou de uma crise político institucional agravada no início de 2015, com a descontinuidade do programa político denominado neodesenvolvimentismo:

Indiscutivelmente, o Brasil melhorou seus indicadores sociais, principalmente aqueles que dizem respeito às camadas pobres do proletariado brasileiro atendidas pelos programas sociais do governo Lula e Dilma. [...] de 2002 a 2013 diminuiu a desigualdade social com a redução da pobreza extrema, aumentou o consumo dos pobres com o crescimento da posse de bensduráveis e 0 acesso a serviços públicos essenciais. ${ }^{07}$

O referido programa apresentava como objetivo a implementação de um conjunto de medidas políticas, econômicas e sociais que visavam, dentre outros fatores, a destinação de recursos públicos para programas de transferência de renda. Segundo a concepção do neodesenvolvimentismo "[...] a superação do subdesenvolvimento brasileiro não ocorre de forma natural e espontânea pelas livres forças do mercado, conforme anteriormente defendido pelos governos neoliberais dos anos 1990". ${ }^{08}$

Notadamente no período denominado neodesenvolvimentismo verificouse a elevação substancial em termos de redução dos níveis de desigualdade, não

\footnotetext{
${ }^{07}$ ALVES, Giovanni. Trabalho e neodesenvolvimentismo: Choque de capitalismo e nova degradação do trabalho no Brasil. Bauru: Praxis, 2014, p. 170.

${ }^{08}$ POCHMANN, Marcio. Políticas públicas e situação social na primeira década do século XXI. In: 10 anos de governos pós-neoliberais no Brasil: Lula e Dilma. Rio de Janeiro: FLACSO, 2013, p. 153.
} 
somente por meio das políticas de transferência de renda presentes durante aquele contexto, mas um "[...] ciclo de prosperidade econômica [...] acompanhado de uma importante dinamização do mercado de trabalho com efeitos muito positivos sobre os estratos mais pobres da população e sobre os assalariados em geral" ${ }^{09}$

$\mathrm{O}$ neodesenvolvimentismo brasileiro começou a apresentar sinais de esgotamento no início do segundo mandato da presidente Dilma. Após a posse, no início de 2015, surgiram indícios de uma acentuada crise política e econômica, acompanhados de anúncios de ajustes fiscais, além de uma série de cortes no orçamento da União. Segundo Braga,

[...] muito frequentemente, é possível observar opiniões creditando o desarranjo da economia à tendência do governo Dilma de controlar preços estratégicos, administrar custos empresariais, diminuir artificialmente os juros, interferir na margem de lucro e descuidar do controle da inflação. ${ }^{10}$

Durante o ano de 2016 houve agravamento da crise política institucional, com uma série de denúncias de corrupção em altos escalões do governo federal e um processo de impeachment que culminou com o afastamento da presidente Dilma Rousseff. Seu sucessor, Michel Temer, assumiu a presidência em meio a uma crise de legitimidade e anunciou uma série de alterações na condução da política econômica no país, dentre elas, a reforma trabalhista, objetivada pelo projeto de lei $6787 / 2016$.

No conturbado contexto do início do governo Temer, o projeto de lei 6787/2016, com propostas de alterações em quase uma centena de artigos da Consolidação da Legislação do Trabalho (CLT) foi apresentado à Câmara dos Deputados para tramitação em caráter de urgência. Na noite de 26 de abril de 2017, o texto do projeto foi aprovado pelo plenário da Câmara e seguiu para a votação pelo Senado. Em 11 de julho do mesmo ano, em uma sessão marcada por protestos tanto favoráveis quanto contrários às alterações da legislação trabalhista, o projeto foi aprovado pelo plenário do Senado, tornando-se a lei 13.467/2017.

Outro ponto bastante polêmico diz respeito à implementação quase que

\footnotetext{
${ }^{09}$ KREIN, José Dari; GIMENEZ, Denis Maracci; Santos,Anselmo Luis dos. Dimensões críticas da reforma trabalbista no Brasil. Campinas: Curt Nimuendajú, 2018, p. 75.

${ }^{10}$ BRAGA, Ruy. Terra em transe: o fim do lulismo e o retorno da luta de classes. In As contradições do lulismo: a que ponto chegamos. SINGER, André; LOUREIRO, Isabel. São Paulo: Boitempo, 2016, p. 55.
} 
imediata da vigência da lei 13.467/2017, em 11 de novembro do mesmo ano. Em outras situações o período denominado vacatio legis, ou seja, o prazo legal para uma lei entrar em vigor (de sua publicação até o início de sua vigência) foi fixado um período claramente inferior ao costumeiro. A título de exemplo, o Código de Direito Civil de 2002 (01 ano) e o Código de Processo Civil de 2015 (01 ano). A reforma trabalhista de 2017 teve um período de vacatio legis de apenas 120 dias. $^{11}$

Sob o discurso da necessidade imediata da modernização das relações trabalhistas, perante o quadro de reestruturação produtiva da ordem econômica mundial, a reforma trabalhista surge como uma das principais medidas para promover o crescimento do país e reverter o contexto de crise/recessão econômica.

A concepção reinante no Brasil de 2016/2017 era a de que a legislação trabalhista ora em vigor, a CLT de 1943, não correspondia ao contexto atual, pois se tornou obsoleta em meio às novas condições de trabalho geradas pelo contexto globalizado e flexibilizado. Mas certamente a legislação que vigorava no momento anterior à reforma não é a mesma de 1943, pois sofreu sucessivas mudanças, em parte produzidas por decisões jurisprudenciais que procuraram aplicar os denominados parâmetros constitucionais, a fim de acompanhar a evolução natural da sociedade. Também a título de exemplo: fundo de garantia (1967), lei de férias (1977), vale-transporte (1985), banco de férias e o trabalho parcial (1998), lei do aprendiz (2000), trabalho feminino (2012-2016), trabalho doméstico (2013-2015) e terceirização $(2017)^{12}$.

Apenas três dias após o início da vigência da reforma trabalhista, o governo de Michel Temer editou uma medida provisória com o objetivo de alterar pontos da recente legislação trabalhista. Pode-se afirmar que a MP 808 acabou funcionando como uma reforma da reforma, pois propôs alterações de pontos geradores de polêmicas durante o período de tramitação da lei 13.467/2017. Em razão da rapidez esperada e da aprovação praticamente imediata junto à Câmara Federal, também o Senado Federal acabou aprovando o texto na íntegra, com o indicativo de uma Medida Provisória para regular os pontos conflitantes que acabariam por atrasar a tramitação da lei.

\footnotetext{
${ }^{11}$ SILVA, Homero Batista Mateus da. Comentários à reforma trabalbista: análise da lei 14.467/2017 - artigo por artigo. São Paulo: Editora Revista dos Tribunais, 2017.

${ }^{12}$ SILVA, Homero Batista Mateus da. Comentários à reforma trabalhista: análise da lei 14.467/2017 - artigo por artigo. São Paulo: Editora Revista dos Tribunais, 2017. p. 10-11.
} 
[...] a presente proposta de Medida Provisória tem por objetivo o aprimoramento de dispositivos pontuais, tais aspectos refletem o profundo processo de diálogo e análise realizado pelo Senado Federal, relacionados a aspectos discutidos durante a tramitação do PLC ${ }^{\circ}$ 38, de 2017, no Senado Federal. Se, por um lado por outro, esta Casa Legislativa observou a desnecessidade de alteração do projeto no momento de sua tramitação, o que implicaria atrasos desnecessários à eficácia deste importante diploma legal. ${ }^{13}$

A Medida Provisória 808/2017, na condição de corrigir os considerados excessos da reforma, propunha alteração de 84 pontos da reforma trabalhista, dentre eles, a jornada de trabalho $12 \times 36$, dano extrapatrimonial, empregada gestante e lactante, autônomo exclusivo, trabalho intermitente, incidência de encargos trabalhista e previdenciária, cobrança e distribuição da gorjeta, representação em local de trabalho, negociado sobre o legislado no enquadramento do grau de insalubridade e arrecadação/contribuição previdenciária. (DIAP, 2017).

A tramitação esperada consistia em inicialmente passar por uma comissão mista, composta por 26 membros titulares e 26 suplentes. Com a aprovação da comissão mista a MP 808/2017 seguiria para a votação no plenário da câmara e, posteriormente, para apreciação do senado federal e sanção pelo presidente Temer. (DIAP, 2017).

Mas o que ocorreu foi que a MP 808 perdeu os seus efeitos, ou seja, não foi apreciada pelo Congresso Nacional dentro do prazo legal permitido e perdeu sua validade, retornando à íntegra do texto da reforma trabalhista aprovado em 11 de julho de 2017. A considerada Medida Provisória de certa forma serviria como um instrumento de adequação do texto da lei 13.467/2017 com alguns questionamentos da sociedade civil, embora prevalecesse seu viés empresarial.

Perante o exposto é possível verificar a inconsistência gerada pelas sucessivas alterações na regulamentação das relações de trabalho no Brasil, pois no período de pouco mais de um ano, houve a apresentação de um projeto de lei (dezembro 2016), a votação da reforma trabalhista (julho 2017), a edição de uma medida provisória para reformar a reforma (novembro de 2017) e o retorno ao texto original da lei $\mathrm{n}^{0}$ 13.467/2017 em razão da perda da validade da medida provisória.

${ }_{13}$ BRASIL. Medida provisória no 808, de 14 de novembro de 2017. Diário Oficial da União - Seção 1 - Edição Extra - 14/11/2017, Página 1 (Publicação Original). Disponível em http://www2.camara.leg.br/legin/fed/ medpro/2017/medidaprovisoria-808-14-novembro-2017-785757-publicacaooriginal-154246-pe.html. Acesso em 12 fev. 2018. 
O resultado inevitável foi insegurança política, social e, principalmente, jurídica resultante de todo esse desenrolar legislativo. Outro resultado foi a conivência do Congresso Nacional com o texto original da reforma aprovado e convertido em lei, considerando que a não votação da citada medida provisória representou o desinteresse por uma parcial adequação do texto anteriormente aprovado.

Como se não bastasse, atualmente tem-se em torno de 24 ações diretas de inconstitucionalidade em tramitação perante do Supremo Tribunal Federal, tendo como objeto combater diversas mudanças promovidas pela reforma trabalhista, que de acordo com as decisões que serão tomadas por aquela corte poder-se-á afirmar que uma terceira reforma está prestes a acontecer, trazendo como consequência imediata uma ainda maior instabilidade jurídica e social nas relações de trabalho, até porque caso as ações vinguem, os textos contaminados com a inconstitucionalidade serão desconstituídos desde o nascedouro, o que resultará em vários problemas diante dos atos praticados sob vigência. ${ }^{14}$

\section{A FLEXIBILIZAÇÃO NAS RELAÇÕES CONTRATUAIS: O NEGOCIADO SOBRE O LEGISLADO}

Em uma sociedade de mercado há a tendência em rotular o trabalho apenas como mecanismo gerador de riquezas, mas o trabalho é, acima de tudo, meio garantidor da efetivação da dignidade da pessoa humana. Tal situação se acentua quando transposto para o mercado global, no contexto da reestruturação produtiva, onde direitos trabalhistas são relegados em nome de uma pretensa modernização das relações de trabalho. Nesse sentido, Azevedo Neto esclarece que na atualidade as formas das relações contratuais acabam gerando efeitos negativos sobre o trabalhador, precarizando o mercado de trabalho e tornando latente a máxima histórica da mão de obra como produto, como mercadoria negociável e sujeita às condições do mercado econômico. ${ }^{15}$

\footnotetext{
${ }_{14}$ São 21 ações diretas de inconstitucionalidade, que questionam diversos itens da chamada nova CLT. Na pauta do Plenário está uma ADI ajuizada pelo então procurador-geral da República, Rodrigo Janot, em oposição ao artigo $1^{\circ}$ da Lei 13.467 , de 13 de julho de 2017, que institui o pagamento de honorários pelo trabalhador. Entre as entidades que se manifestam pela inconstitucionalidade das normas objeto da ação, a Central Única dos Trabalhadores (CUT), a Central Geral dos Trabalhadores do Brasil (CTGB), a Central dos Sindicatos Brasileiros (CSB) e a Associação Nacional dos Magistrados da Justiça do Trabalho (Anamatra). (Supremo começa a julgar ações que questionam a reforma trabalhista, Consultor Jurídico, 3,05.2018, https:// www.conjur.com.br/2018-mai-03/supremo-comeca-julgar-acoes-questionam-reforma-trabalhista, capturado em 05.07.2018).

${ }^{15}$ AZEVEDO NETO, Platon Teixeira de. O trabalho decente como um direito humano. São Paulo: LTr, 2015, p. 49.
} 
Segundo artigo $1^{\circ}$, inciso IV da Constituição Federal de 1988, a "República Federativa do Brasil [...] tem como fundamentos [...] inciso IV - os valores sociais do trabalho e da livre iniciativa". ${ }^{16}$ Nesse sentido, conclui-se que o trabalho deve ser interpretado como direito fundamental, assim como um instrumento de obtenção da dignidade da pessoa humana. Juntamente com a livre iniciativa, o trabalho representa um dos princípios constitucionais que assegura a dignidade da pessoa humana, posicionando-se de maneira superior às demais normas infraconstitucionais.

Seguindo os preceitos constitucionais que enaltecem o valor social do trabalho, é possível citar o artigo $3^{\circ}$, onde se esclarece que

[..] constituem objetivos fundamentais da República Federativa do Brasil: I - construir uma sociedade livre, justa e solidária; II - garantir o desenvolvimento nacional; III - erradicar a pobreza e a marginalização e reduzir as desigualdades sociais e regionais; IV - promover o bem de todos, sem preconceitos de origem, raça, sexo, cor, idade e quaisquer outras formas de discriminação. ${ }^{17}$

Nos artigos $6^{\circ}$ e $7^{\circ}$ o trabalho é colocado como direito social e, por fim, o artigo $17^{\circ}$ estabelece que

A ordem econômica, fundada na valorização do trabalho humano e na livre iniciativa, tem por fim assegurar a todos existência digna, conforme os ditames da justiça social, observados os seguintes princípios [...] VI - redução das desigualdades regionais e sociais; VIII - busca do pleno emprego.

As normas emanadas da legislação federal destinam-se à satisfação e à garantia dos direitos dos trabalhadores, contribuindo para a efetivação de seu valor social, colocando-o como um instrumento de concretização da dignidade da pessoa

${ }^{16}$ BRASIL. Medida provisória no 808 , de 14 de novembro de 2017. Diário Oficial da União, Seção 1, Edição Extra, 14/11/2017, Página 1 (Publicação Original). Disponível em http://www2.camara.leg.br/legin/fed/medpro/2017/ medidaprovisoria-808-14-novembro-2017-785757-publicacaooriginal-154246-pe.html. Acesso em 12 fev. 2018.

${ }^{17}$ BRASIL. Medida provisória no ${ }^{\circ}$ 808, de 14 de novembro de 2017. Diário Oficial da União, Seção 1, Edição Extra, 14/11/2017, Página 1 (Publicação Original). Disponível em http://www2.camara.leg.br/legin/fed/medpro/2017/ medidaprovisoria-808-14-novembro-2017-785757-publicacaooriginal-154246-pe.html. Acesso em 12 fev. 2018. 
humana. A partir do momento em que a flexibilização da legislação trabalhista contraria princípios constitucionais deixa de ser legítima e constitucional. Por ser o trabalho o instrumento de garantia de sobrevivência do trabalhador, responsável pela manutenção de condições dignas de saúde, educação, moradia, deve ser protegido, por ser considerado principalmente como o fundamento da República Federativa, com vistas a preservar e assegurar a dignidade da pessoa humana.

Com o objetivo de ressaltar a precarização das relações contratuais, promovidas pela flexibilização da legislação trabalhista a análise segue com alguns apontamentos relativos à jornada de trabalho regulada por acordo individual, ou seja, o negociado sobre o legislado, eleita em razão da agressão direta às mínimas proteções referentes à segurança e à saúde do trabalhador.

A aprovação pelo Senado Federal da lei $13.467 / 2017$ possibilitou mais de uma centena de alterações na CLT, dentre elas a possibilidade da celebração de acordos e convenções coletivas de trabalho, supostamente com o objetivo de flexibilizar as relações de trabalho, promovendo por meio de negociações coletivas a alteração daquilo que antes estava disposto por normas de ordem pública.

A questão do negociado sobre o legislado foi um dos pontos polêmicos da denominada modernização das relações trabalhistas, pois se por um lado a flexibilização contratual serviria como uma forma de modernizar as relações de trabalho e permitir aumento na oferta de empregabilidade por outro lado significaria um retrocesso em termos de direitos trabalhistas, pois há que se considerar que o trabalhador, por ser a parte mais frágil da relação, deveria ser considerado hipossuficiente. De forma contrária, partiu-se de uma realidade inexistente, ou seja, que empregador e empregado estariam economicamente em condições de igualdade. Ou, que pela negociação coletiva, composta principalmente com a participação do sindicato representante da categoria profissional, deixaria de haver qualquer desigualdade entre categoria profissional e econômica.

Segundo o disposto no artigo 444 do decreto-lei $\mathrm{n}^{0} 5.452$, de $1^{\circ}$ de maio de 1943, "As relações contratuais de trabalho podem ser objeto de livre estipulação das partes interessadas em tudo quanto não contravenha às disposições de proteção ao trabalho, aos contratos coletivos que lhes sejam aplicáveis e às decisões das autoridades competentes". ${ }^{18}$

Em termos de legislação trabalhista, o artigo 444 determina que as condições

${ }^{18}$ CLT. CONSOLIDAÇÃO DAS LEIS DO TRABALHO. Decreto-lei $\mathrm{n}^{0}$ 5.452. Atualizada com a Reforma Trabalhista - Lei n ${ }^{0}$ 13.467, de 13 de junho de 2017. São Paulo: Edipro, 2017, p. 96. 
de trabalho deverão estar sujeitas necessariamente às restrições da legislação social e normas coletivas, tornando a liberdade contratual quase nula. Nesse sentido, "[...] é ele que embasa a fixação do turno de trabalho, do salário, das funções a serem exercidas e de cláusulas acessórias, mas evidentemente com peso muito maior da opinião do empregador do que na vontade do empregado". ${ }^{19}$

Após as alterações no texto da lei foi inserido um parágrafo único ao artigo 444, em que

[... ] a livre estipulação a que se refere o caput deste artigo aplicase as hipóteses previstas no art. 611-A desta Consolidação, com a mesma eficácia legal e preponderância sobre os instrumentos coletivos, no caso de empregado portador de diploma de nível superior e que perceba salário mensal ou superior a duas vezes o limite máximo dos benefícios do Regime Geral de Previdência Social. ${ }^{20}$

Nesse contexto criou-se a figura do trabalhador hipersuficiente, ou seja, aquele que tem curso superior e um salário de aproximadamente $\mathrm{R} \$ 11.062,62$, o que, supostamente o colocaria em uma posição privilegiada e com condições de negociar diretamente com o empregador seu contrato de trabalho.

Nota-se que o legislador faz referência ao art. 611-A, aplicando o caput a todas as hipóteses previstas (15 incisos), estabelecendo diferentes condições em que o negociado prevalece sobre o legislado. Embora um pouco longa a transcrição a seguir faz-se necessária para o esclarecimento de diferentes situações em que prevalece o negociado.

Observa-se que na redação do caput do artigo 61 a "convenção coletiva e o acordo coletivo de trabalho têm prevalência sobre a lei quando, entre outros [...]"21 a expressão "dentre outros", ou seja, não há limites para situações em que terá prevalência o negociado sobre o legislado, acarretando absoluta insegurança nas relações de trabalho.

No momento em que o acordo individual se sobrepõe à norma codificada e a convenção coletiva "subverte o princípio da norma mais favorável, em afronta ao art. $7^{\circ}$, caput, mas também ignora o reconhecimento das normas coletivas como

\footnotetext{
${ }_{19}$ SILVA, Homero Batista Mateus da. Comentários à reforma trabalhista: análise da lei 14.467/2017 - artigo por artigo. São Paulo: Editora Revista dos Tribunais, 2017, p. 70.

${ }^{20}$ CLT. Op. cit.

21 Op. cit.
} 
fonte de direito, expressado pelo artigo $7^{\circ}$, XXVI" ${ }^{22}$ Relativo ao princípio da norma mais favorável entende-se que quando há conflito de normas prevalece aquela mais favorável ao trabalhador, que lhe traga maiores benefícios. No direito do trabalho a inconstitucionalidade se verifica quando uma norma hierarquicamente inferior vier a transgredir uma norma superior, nesse caso, uma determinação constitucional.

A Constituição Federal impõe a participação de toda a sociedade na valorização do ser humano, estabelecendo para tanto garantias e instrumentos processuais adequados, tratando-se de resultados do meio histórico e político (pensamento de Robert Alexy). Ao mesmo tempo, Alexandre de Moraes leciona que a Constituição Federal é garantidora de todo o ordenamento jurídico em relação às garantias fundamentais para todos, de forma indistinta, sendo que o artigo $1^{\circ}$, inciso III, estabeleceu todo o "aparato constitucional" para a tutela da pessoa humana, ou seja,

A dignidade é um valor espiritual e moral inerente à pessoa, que se manifesta singularmente na autodeterminação consciente e responsável da própria vida e que traz consigo a pretensão ao respeito por parte das demais pessoas, constituindo-se um mínimo invulnerável que todo estatuto jurídico deve assegurar, de modo que, somente excepcionalmente, possam ser feitas limitações ao exercício dos direitos fundamentais, mas sempre sem menosprezar a necessária estima que merecem todas as pessoas enquanto seres humanos ${ }^{23}$.

Nesse sentido há que salientar também o inciso XIII do referido artigo, pois estabelece que a duração do trabalho normal não pode ser superior a 08 horas diárias e 44 semanais, "[...] facultada a compensação de horários e a redução da jornada, mediante acordo coletivo ou convenção coletiva de trabalho. "24 Enaltecendo a importância das normas coletivas, previstas constitucionalmente, como fonte geradora e garantidora dos direitos trabalhistas.

Relativo às condições proporcionadas pelo negociado sobre o legislado, tem-se que o número de convenções coletivas (celebradas entre forças sindicais patronais e laborais) concluídas no primeiro trimestre de 2018 foi $42.9 \%$ menor que

\footnotetext{
${ }_{22}$ SILVA, Homero Batista Mateus da. Comentários à reforma trabalhista: análise da lei 14.467/2017: artigo por artigo. São Paulo: Editora Revista dos Tribunais, 2017, p. 208.

${ }^{23}$ MORAES, Alexandre de. Direito Constitucional. 17.ed. São Paulo: Atlas, 2005, p. 16.

${ }^{24}$ CLT. Op. cit. p. 145.
} 
no mesmo período de 2017, indicando a intensificação da realização do negociado sobre o legislado, já como reflexo da reforma nas relações de trabalho promovidas pela lei $14.467 / 2017 .^{25}$

Diante do exposto observa-se contrariedade do parágrafo único do artigo 444 em comparação ao estabelecido constitucionalmente, especificamente o caput do art. $7^{\circ}$, em que enaltece a legislação trabalhista em benefício da melhoria da condição social do trabalhador e não o seu contrário, ou seja, intensificar a degradação das condições contratuais e, por consequência, das condições de trabalho.

Para Lourival José de Oliveira e Mayra Figueiredo,

No embate entre capital e trabalho, as transformações no mundo laboral atraem a regulamentação do direito nos mesmos moldes. A modernização dessas relações requer, em uma abordagem econômica, a modernização da legislação trabalhista. Contudo, qualquer pensamento de alteração da legislação do trabalho, nessa perspectiva de mudanças, exige a manutenção da raiz axiológica do Direito do Trabalho, de proteção à condição humana do trabalhador.

$[\ldots]$

A Lei 13.467 , de 13 de julho de 2017 , chamada de reforma trabalhista, que trouxe profundas modificações na Consolidação das Leis do Trabalho (CLT), parece caminhar em sentido oposto. Em primeiro lugar, por restringir a intervenção do Estado, quer pela inibição do Poder Judiciário no controle de cláusulas normativas (artigo $8^{\circ}, \S 3^{\circ}$ ), quer pela institucionalização da prevalência do negociado sobre o legislado (especialmente artigo 611-A). Ainda, porque esfacela, sem exageros, o princípio protetor, desconsiderando a real vulnerabilidade do trabalhador para equipará-lo, de certa forma, à figura do empregador. ${ }^{26}$

Sendo assim, fica difícil através da ótica constitucional sustentar as mudanças da reforma trabalhista, considerando a sua incompatibilidade, em especial em

\footnotetext{
25 DIAP. Departamento Intersindical de Assessoria Parlamentar. MP 808/17 recebeu 967 emendas na comissão mista do Congresso. Disponível em: http://www.diap.org.br/index.php/noticias/agencia-diap/27731-reformatrabalhista-mp-808-17-recebe-967-emendas-na-comissao-mista. Acesso em: 19 maio 2017.

${ }^{26}$ OLIVEIRA, Lourival José. FIGUEIREDO, Mayra Freire. A reforma trabalhista e liberdade contratual: o direito ao trabalho construído sob a perspectiva puramente econômica. Revista de Direito Econômico e Socioambiental, v.08, no 03, 2017, p. 93 a 121. Disponível em: https://periodicos.pucpr.br/index.php/direitoeconomico/article/ view/18405/22578. Acesso em 16.06.2018.
} 
relação ao contido no artigo $1^{\circ}$, incisos III e IV, em que se destacou a proteção ao valor social do trabalho. Sem perder continuidade e simultaneamente, vale aqui frisar o contido no artigo 170 também da Constituição Federal, que estabeleceu como base da ordem econômica a valorização do trabalho humano. Ainda, na forma do artigo 193, o trabalho constitui o primado da ordem social, tratando-se de direito fundamental e em assim sendo é possível afirmar que se encontra protegido contra o poder de reforma (artigo 60, parágrafo $4^{\circ}$, inciso IV da C.F.).

É muito importante destacar que a Constituição Federal reconheceu a centralidade do trabalho na vida pessoal e comunitária do indivíduo, garantindo a "essencialidade da conduta laborativa como um dos instrumentos mais relevantes de afirmação do ser humano, quer no plano de sua própria individualidade, quer no plano de sua inserção familiar e social". ${ }^{27}$

A Constituição reconheceu, portanto, a centralidade do trabalho na vida pessoal e comunitária do indivíduo, garantindo a "essencialidade da conduta laborativa como um dos instrumentos mais relevantes de afirmação do ser humano, quer no plano de sua própria individualidade, quer no plano de sua inserção familiar e social" ${ }^{28}$ Reconheceu, pois, o trabalho como condição de vida digna e, por isso mesmo, na lógica constitucional, deve ser interpretado de forma indissociável da dignidade da pessoa humana.

Do mesmo modo, o relevo à autonomia individual trazido com a Lei 13.467/2017 não convence. Em uma relação jurídica marcada pela sujeição do trabalhador ao poder do empregador, aliada ao mesmo contexto de desemprego1 e relações de emprego desprotegidas contra a despedida imotivada, a dita liberdade contratual não prevalece, não havendo espaço, no terreno dos fatos, para a autonomia da vontade obreira. ${ }^{29}$

O Ministério Público do Trabalho já se posicionou sobre a liberdade contratual individual relevada pela reforma. Ao analisar as disposições do artigo 444,

\footnotetext{
${ }^{27}$ DELGADO, Maurício Godinho. Direitos Fundamentais na Relação de Trabalho. Revista de Direitos e Garantias Fundamentais. n. 2, 2007. Disponível em: http://sisbib.fdv.br/index.php/direitosegarantias/article/ viewFile/40/38. Acesso em: 15 jun. de 2018. p. 15.

${ }^{28}$ Op. cit.

${ }^{29}$ OLIVEIRA, Lourival José. FIGUEIREDO, Mayra Freire. A reforma trabalhista e liberdade contratual: o direito ao trabalho construído sob a perspectiva puramente econômica. Revista de Direito Econômico e Socioambiental, v. $08, \mathrm{n}^{\circ} 03,2017$, p. 93 a 121. Disponível em: https://periodicos.pucpr.br/index.php/direitoeconomico/article/ view/18405/22578 Acesso em 16.06.2018.
} 
parágrafo único, combinado com o artigo 611-A, acima citado, todos da CLT, afirmou se tratarem de "[...] derrogação pura e simples de qualquer proteção jurídicotrabalhista quanto aos principais elementos da relação trabalho subordinado". ${ }^{30}$

O que precisa ser entendido é que o aumento das possibilidades de pactos individuais e ou coletivos, possibilitadas pela reforma trabalhista, não possui outra finalidade a não ser propiciar um ambiente capaz de concretizar o modelo liberal, envolvendo também os direitos sociais. Com isso tem-se a desconstituição do valor social do trabalho, que na forma aqui apresentada, se constitui no princípio maior e fundamental da ordem constitucional. Trata-se de justamente estabelecer uma igualdade entre as partes que não existe no campo fático. Trata-se de comprometer toda a estrutura normativa constitucional.

$\mathrm{O}$ órgão ministerial ainda concluiu pela inconstitucionalidade da autorização legislativa sobre a livre negociação do conteúdo do contrato de trabalho subordinado, em patamar inferior ao previsto na lei (artigo $7^{\circ}$, I da Constituição) ou na negociação coletiva (artigo $7^{\circ}$, XXVI da Constituição), visto que a Constituição admite flexibilização de direitos expressamente pela negociação coletiva e não por acordo individual. ${ }^{31} \mathrm{E}$ ainda que por negociação coletiva, também deve ser respeitado o valor trabalho humano aliado à finalidade que é a produção de dignidade.

Parece-me que um primeiro e importante passo a ser dado na direção da humanização das relações de trabalho dos altos empregados é reconhecer que, mesmo tendo alto padrão de conhecimento técnico e sendo portadores de uma cultura mais elevada que o padrão médio dos demais empregados, não deixam de depender economicamente do emprego (aliás, há uma dependência até moral ao emprego, dada a necessidade natural de manutenção do seu status social) e que, por conta disso, submetem-se às regras do jogo capitalista para não perderem sua inserção no mercado. Sua sujeição às condições de trabalho que lhe são impostas pela lógica da produção é inevitável. ${ }^{32}$

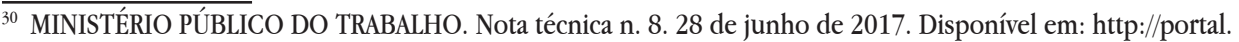
mpt.mp.br/wps/wcm/connect/portal_mpt/204a16b7-0bca-409d-a7fd-. Acesso em 19 agosto de 2017.

${ }^{31}$ OLIVEIRA, Lourival José. FIGUEIREDO, Mayra Freire. A reforma trabalhista e liberdade contratual: o direito ao trabalho construído sob a perspectiva puramente econômica. Revista de Direito Econômico e Socioambiental, v.08, $\mathrm{n}^{\mathrm{O}}$ 03, 2017, p. 93 a 121. Disponível em: https://periodicos.pucpr.br/index.php/direitoeconomico/article/ view/18405/22578. Acesso em 09 jul. 2018.

32 SOUTO MAIOR, Jorge Luiz de. Do direito à desconexão do trabalho. 2003, p. 08. Disponível em: http://www. jorgesoutomaior.com/uploads/5/3/9/1/53916439/do_direito_\%C3\%A0_desconex\%C3\%A3o_do_trabalho.. pdf. Acesso em: 19 ago. 2017.
} 
Não existe padrão técnico (qualificação) ou valor remuneratório que possa sobrepor à desigualdade existente entre empregado e empregador. Ainda que existente os dois elementos, não pode ser afirmado que se construiu um plano de igualdade capaz de fazer prevalecer o processo de negociação inclusive sobre normas de ordem pública, justamente por conta que o valor trabalho humano se constitui em um direito fundamental.

Criou-se por meio da reforma trabalhista (artigo $8^{\circ}$, parágrafo $3^{\circ}$ da CLT) o princípio da intervenção mínima da autonomia da vontade das partes, sem que houvesse uma construção social que fosse suficiente para sustentar essa nova regra, em especial pela fragilidade em que ocorrem os processos de negociações coletivas do trabalho.

\section{A FRAGILIDADE DO PROCESSO DE NEGOCIAÇÃO COLETIVA}

Em continuidade à análise, outra questão que não pode ser esquecida diz respeito ao não desenvolvimento dos processos de negociação coletiva no Brasil. Quando se estabelece constitucionalmente a negociação coletiva inclusive como forma de solução de conflitos do trabalho (artigo 114, parágrafo $1^{\circ}$ da C.F.), o objetivo constitucional é a progressividade dos direitos sociais e não o inverso, tanto que a Constituição Federal de forma pontual (artigo $7^{\circ}$ ), pontuou situações, como é o caso da redução salarial ou mesmo da compensação de jornada de trabalho, em que a negociação deverá estar presa ao vetor constitucional dignidade da pessoa humana.

A edificação de um direito do trabalho efetivo e eficaz permite a consolidação e a afirmação de uma sociedade verdadeiramente democrática. Os sindicatos, por sua vez, representam importante instrumento de desenvolvimento do direito do trabalho, seja por meio das lutas por melhores condições de trabalho e vida, seja pelo elo de identidade que firmam entre o sujeito trabalhador e sua classe. Além disso, a postura do Estado capitalista - compelido a aceitar como legais e legítimas as organizações sindicais - sempre esteve vinculada à capacidade de mobilização dos trabalhadores.

A fundamentação do sindicalismo para a implementação e para o aperfeiçoamento da democracia pode ser percebida, também, a partir da 
consagração da liberdade sindical como direito humano. Não sem razão, as principais Constituições contemporâneas incorporaram, em seu arcabouço normativo, os direitos trabalhistas e princípios sindicais a fim de efetivá-los.

No Brasil, porém, o sistema sindical viu-se refreado pelos desarranjos do corporativismo. A partir da década de 1930, o Estado cooptou o sindicalismo e os fenômenos de interação coletiva dele decorrentes, retirando-lhes a essência de liberdade intrínseca presente em sua consolidação histórica.

Estruturalmente enrijecido e organizacionalmente abalado, o sindicalismo brasileiro não foi capaz de se reconstruir, nem mesmo diante das atribulações cíclicas do sistema capitalista. Isso influenciou diretamente no aprofundamento da crise sindical, a contar das décadas de 1980 e 1990, quando o neoliberalismo - e os modelos de reestruturação produtiva dele decorrentes - conseguiu hegemonizar sua agressiva política econômica.

A partir da promulgação da Constituição da República de 1988, porém, foram estabelecidos paradigmas democráticos que, decerto, percebiam-se incompativeis com o modelo sindical até então consolidado no país.

No entanto, desprezando o potencial renovatório incrustrado no novel Estado democrático de Direito, a doutrina e jurisprudência majoritárias sorveram e verteram um discurso ideológico desalinhado dos axiomas constitucionais recém-inaugurados. Negaram, por meio da apreensão dos ideários corporativos e sem a adequada filtragem constitucional, a emancipação jurídica do sindicalismo, mantendo-o aprisionado pelos padrões de uma legislação nitidamente inassimilável pela nova ordem constitucional.

Sem dúvida que uma reforma trabalhista somente poderia acontecer, e ainda assim em etapas, com a participação da sociedade, desde que tivesse ocorrido uma reforma na organização sindical, capaz de permitir que efetivamente houvesse um negociado. Da forma como a reforma/2017 se apresentou, tendo como ponto central o "legislado sobre o negociado", e diante da fragilidade e ou inoperância das organizações sindicais, é como se deixasse o trabalhador entregue à sua própria sorte.

Melhor explicando, no Brasil, é possível afirmar que após a Constituição de 1988 ocorreu certa "flexibilização" no direito do trabalho, comprovadamente quando se permitiu que pelo acordo coletivo ou convenção coletiva se dispusesse sobre jornada de trabalho ou redução de salários, por exemplo (artigo $7^{\circ}$, incisos VI 
e XIII da C.F.), seguindo-se os procedimentos previamente estabelecidos.

A característica histórica do Estado brasileiro consiste em um Estado intervencionista, ou seja, a negociação coletiva não se desenvolveu suficientemente como meio pelo qual devem ser obtidas outras regulações das relações de trabalho em face da rapidez das transformações imprimidas pela economia globalizante.

E é justamente esse um dos pontos, que independentemente da inconstitucionalidade da reforma trabalhista, também deve ser debatida. Trata-se da possibilidade ou não de efetivamente estabelecer-se negociações coletivas de trabalho na forma preconizada pelo artigo 611-A da CLT. Sendo assim, primeiro têmse situações completamente inconstitucionais conforme anteriormente exposto e, além disso, mesmo que não fossem, ainda se tem o problema da dificuldade de serem implementados processos de negociação coletiva laboral no Brasil por conta de as organizações sindicais terem se desenvolvido como dependente do Estado, como também pela deslocação de poder e pela abrangência que deve possuir em face da globalização.

Evidentemente que houve um deslocamento do poder, incluindo-se um deslocamento da própria órbita das negociações coletivas de trabalho, que antes tinha abrangência nacional e agora deve ocorrer por setores da produção e de forma regionalizada, ultrapassando as fronteiras do mercado nacional e implicando, por sua vez, a redução da força sindical, caso seja mantido seu atual modelo (no caso do Brasil). Ocorre que referida 'redução de poder' do sindicato deve-se em parte à manutenção do mesmo instrumental do passado, devido a determinada estrutura política, social e econômica, que passou por mudanças, sem que essas ocorressem na órbita do movimento dos trabalhadores. Diga-se, mesmo nos meios em que se admite a ampla liberdade sindical, como é o caso europeu, com pluralidade e autonomia interna pode ser tecida a mesma crítica aqui apresentada, uma vez que, também naqueles países, ocorreu uma perda gradual de representação a contar principalmente da década de $70 .{ }^{33}$

Romita, em artigo publicado antes da edição da Constituição Federal vigente, tratando sobre o direito do trabalho e a democracia brasileira, defendia a tese de que

33 OLIVEIRA, Lourival José. Direito do Trabalho: organizações de trabalhadores e modernização. Curitiba: Juruá, 2003. p. 56. 
a legislação do trabalho vigente à época não compadecia com o regime democrático, fundamentando sua colocação no fato que a legislação em vigor estava baseada na política do denominado Estado Novo, caracterizado como autoritário e ditatorial, corporativo, para não dizer repressor das aspirações da classe trabalhadora. Citando Giuliano Mazzoni, Romita acrescentou que

No regime corporativo, a legislação do trabalho está longe de ser protecionista. Não move o Estado corporativo qualquer intuito de 'proteger' as classes trabalhadora. No dizer de Giuliano Mazzoni, 'o ordenamento corporativo admite a realidade de interesses coletivos diversos e opostos entre as categorias, mas supera tal oposição mediante a colaboração coletiva'. Os fins do Estado se realizam com a mescla dos interesses conflitantes em vista do superior interesse nacional e a subordinação dos interesses coletivos de categoria aos interesses coletivos da Nação, representados pelo Estado. ${ }^{34}$

Por todos esses motivos, Romita ainda afirma que "apregoado 'princípio protecionista' não passa, como parece evidente, de mera cortina de fumaça com que se procura ocultar - e, se possível, perpetuar - a verdadeira face autoritária e corporativista da vigente legislação do trabalho". ${ }^{35}$

Segundo Klippel, qualquer atividade relacionada à flexibilização das relações de trabalho deverá considerar o equilíbrio entre três importantes pilares do direito do trabalho: princípio da proteção ao trabalhador, manutenção dos direitos garantidores da dignidade humana e a necessidade de manutenção da saúde da empresa. $^{36}$

Deve-se também levar em conta que o fenômeno da expansão das cadeias produtivas, nas quais a terceirização ganhou força no processo histórico mais recente, promoveu a denominada dificuldade de identificação do próprio empregador, com a difusão e criação de novos sindicatos representantes de prestadores de serviços das mais variadas espécies, o que poderá contribuir com o esvaziamento ainda maior da própria representação sindical. Nesse contexto, é possível afirmar que no sentido contrário ao preconizado pela reforma trabalhista, ainda maiores dificuldades surgirão no processo de negociação coletiva.

\footnotetext{
34 MAZZONI apud ROMITA, Arion Sayão. Direito do trabalho para uma (possível?) democracia brasileira. Revista LTr, São Paulo, v. 49, n. 12, p. 1.417-1.430, 1985, p. 142.

${ }^{35}$ Op. cit.

${ }^{36}$ KLIPPEL, Bruno. Jornada de trabalho e Direitos Fundamentais. São Paulo: LTr, 2016, p. 24-25.
} 
Como um dos princípios elencados pela Constituição Federal, o trabalho deve ser interpretado como direito fundamental, assim como um instrumento de obtenção da dignidade da pessoa humana. Juntamente com a livre iniciativa, o trabalho representa um dos princípios constitucionais, posicionando-se de maneira superior às demais normas infraconstitucionais.

O que se observa com o novo regramento entabulado pela reforma trabalhista foi na verdade a tentativa de criar condições inconstitucionais para que houvesse o esvaziamento dos direitos sociais, na tentativa de proporcionar uma verdadeira renúncia desses mesmos direitos. Não houve qualquer tentativa de criação de condições concretas para a existência quer seja de negociação coletiva ou de outra forma para solução dos conflitos advindos do trabalho. Também, em nenhum momento procurou-se priorizar a garantia da cláusula do não retrocesso social. Segundo Francisco Gerson Marques de Lima,

Estranhamente, a referida Lei reformista não expressou nenhum esforço em: (a) estimular as negociações coletivas, o que seria possível mediante criação de condições reais e jurídicas de autocomposição, com mecanismos eficazes

e dialogais; (b) garantir igualdade negocial entre os atores, pois enfraqueceu

os sindicatos, deixando o equilíbrio negocial comprometido; (c) estabelecer entre as partes proteção efetiva ao negociado, limitando-se a reduzir a intervenção do Estado nos instrumentos coletivos, enquanto nada inovou na

obrigatoriedade dos atores em honrar as cláusulas negociadas; (de demonstrar preocupação com o princípio da vedação do retrocesso social, pois pretendeu tornar negociáveis garantias de saúde, segurança do trabalho e direitos há muito consagrados (veja-se o art. 611-B, parág. único, CLT); (e) privilegiar os canais autocompositivos, como a mediação, a conciliação e a arbitragem, na instrumentalização institucional das negociações coletivas. No geral, percebesse que a intenção do legislador foi a de criar um arremedo de negociação coletiva, na qual será possível a entrega e a renúncia de direitos por entidades fragilizadas, com instrumentos coletivos infensos ao reexame do Judiciário. ${ }^{37}$

37 LIMA, Francisco Gerson Marques de. Instrumentos Coletivos de Trabalho , num contexto de reforma trabalhista. Revista do Programa de Pós Graduação da UFC, v.37.2, jul/dez de 2017, p. 378 e 379. Disponível em: http://www.periodicos.ufc.br/nomos/article/view/30916/71812. Acesso em 09 jul. 2017. 
O valor trabalho, com a reforma trabalhista, passa a ser tratado no aspecto puramente econômico, esquecendo-se o legislador de seu status de direito fundamental social. A condição humana dá lugar, mais uma vez na evolução da história, à coisificação do trabalhador, constituindo-se em uma violência contra a constituição. A reforma trabalhista, em analisando o seu maior propósito, que é fazer prevalecer o negociado sob o fundamento da modernidade laboral, tentou criar uma realidade fática que não existe e sobre ela constituir processos para a redução dos direitos sociais.

\section{CONSIDERAÇÕES FINAIS}

Não há como questionar as transformações ocorridas em nível mundial e a influência das referidas transformações nas instituições presentes no processo. Também inegável que o atual contexto econômico acarretou transformações no processo produtivo, considerando que com a sua reestruturação foram criados diferentes ambientes e formas de exercer o trabalho, inclusive com a extensão da jornada pelo uso da tecnologia e o aviltamento de regras de proteção e segurança no trabalho. Mas o que importa salientar é a questão valorativa do trabalho como fundamento constitucional, como parte integrante do Estado democrático do Direito.

No polêmico contexto das reformas políticas e econômicas a reforma trabalhista e consequente flexibilização das relações de trabalho, em concordância ao discurso da necessidade de modernização e adequação à nova ordem, acabou promovendo instabilidade e precarização, alterando substancialmente sua concepção jurídica.

A questão do negociado sobre o legislado foi um dos pontos polêmicos da denominada modernização das relações trabalhistas, pois se por um lado a flexibilização contratual serviria como uma forma de modernizar as relações de trabalho e permitir aumento na oferta de empregabilidade por outro lado significou um retrocesso em termos de direitos trabalhistas, pois há que se considerar que o trabalhador, por ser a parte mais frágil da relação, deveria ser considerado hipossuficiente. De fato, talvez esse seja o ponto principal da reforma, ou seja, criar um ambiente fictício em que empregado e empregador não teriam qualquer desigualdade econômica. 
A reforma trabalhista empreendida no Brasil reflete os mecanismos de perpetuação das desigualdades sociais, manifestando claramente objetivos com vistas à reprodução e manutenção da precariedade das relações de trabalho no Brasil. Além de um desacordo latente com os princípios constitucionais que asseguram as condições de valorização do trabalho.

\section{REFERÊNCIAS}

ALVES, Giovanni. Trabalho e neodesenvolvimentismo: Choque de capitalismo e nova degradação do trabalho no Brasil. Bauru: Praxis, 2014.

ALVES, Giovanni. A tragédia de Prometeu: a degradação da pessoa-humana-quetrabalha na era do capitalismo manipulatório. Bauru: Projeto Editorial Praxis. 2016.

AZEVEDO NETO, Platon Teixeira de. O trabalho decente como um direito humano. São Paulo: LTr, 2015.

BELLUZO, Luiz Gonzaga; GALÍPOLO, Gabriel. Manda quem pode, obedece quem tem prejuízo. São Paulo: Contracorrente, 2017.

BRAGA, Ruy. Terra em transe: o fim do lulismo e o retorno da luta de classes. In As contradições do lulismo: a que ponto chegamos. São Paulo: Boitempo, 2016

BRASIL. Medida provisória $\mathrm{n}^{\circ}$ 808, de 14 de novembro de 2017. Diário Oficial da União - Seção 1 - Edição Extra - 14/11/2017, p. 1. Disponível em: http://www2. camara.leg.br/legin/fed/medpro/2017/medidaprovisoria-808-14-novembro-2017785757-publicacaooriginal-154246-pe.html

CLT. Consolidação das Leis do Trabalho. Decreto-lei no 5.452. Atualizada com a Reforma Trabalhista - Lei no 13.467, de 13 de junho de 2017. São Paulo: Edipro, 2017.

CONSELHO NACIONAL DA INDUSTRIA (CNI). 101 Propostas para a Modernização Trabalhista. Brasília, 2012. Disponível em: http://bucket-gw-cni-static-cms-si.s3.amazonaws.com/legacy/app/ conteudo_18/2012/12/04/2728/20121204160144687771i.pdf. Acesso em: fev. 2018. 
DELGADO, Maurício Godinho. Direitos Fundamentais na Relação de Trabalho.

Revista de Direitos e Garantias Fundamentais, n. 2, 2007. Disponível em: http:// sisbib.fdv.br/index.php/direitosegarantias/article/viewFile/40/38. Acesso em: 15 junho 2018.

DIAP. Departamento Intersindical de Assessoria Parlamentar. MP 808/17 recebeu 967 emendas na comissão mista do Congresso. Disponível em: http://www.diap.org.br/ index.php/noticias/agencia-diap/27731-reforma-trabalhista-mp-808-17-recebe-967emendas-na-comissao-mista. Acesso em: 19 maio 2017.

FERRER, W.M.H.; ROSSINHOLI, M. Constituição Federal e direitos sociais: uma análise econômica e social do atual estado brasileiro. Revista Argumentum. Marília, v. 19, n. 1, pp. 27-50, Jan.-Abr. 2018. Disponível http://ojs.unimar.br/index.php/ revistaargumentum/article/view/557. Acesso em 09 de julho de 2018.

KLIPPEL, Bruno. Jornada de trabalho e Direitos Fundamentais. São Paulo: LTr, 2016.

KREIN, José Dari; GIMENEZ, Denis Maracci; SANTOS, Anselmo Luis dos. Dimensões críticas da reforma trabalhista no Brasil. Campinas: Curt Nimuendajú, 2018

LIMA, Francisco Gerson Marques de. Instrumentos Coletivos de Trabalho, num contexto de reforma trabalhista. Revista do Programa de Pós Graduação da UFC, v. 37.2, jul/dez de 2017, p. 378 e 379.

OLIVEIRA, Lourival José. FIGUEIREDO, Mayra Freire. A reforma trabalhista e liberdade contratual: o direito ao trabalho construído sob a perspectiva puramente econômica. Revista Revista de Direito Econômico e Socioambiental, v. 8, n. 3, 2017, p. 93 a 121. Disponível em: https://periodicos.pucpr.br/index.php/direitoeconomico/ article/view/18405/22578. Acesso em: 16 jun. 2018.

OLIVEIRA, Lourival José. Direito do Trabalho: organizações de trabalhadores e modernização. Curitiba: Juruá, 2003.

POCHMANN, Marcio. Políticas públicas e situação social na primeira década do século XXI. In: 10 ANOS de governos pós-neoliberais no Brasil: Lula e Dilma. Rio de Janeiro: FLACSO, 2013. 
ROESLER, Átila da Rold. Crise econômica, flexibilização e o valor social do trabalho. São Paulo, LTr, 2014.

ROMITA, Arion Sayão. Direito do trabalho para uma (possível?) democracia brasileira. Revista LTr, São Paulo, v. 49, n. 12, p. 1.417-1430, 1985.

SILVA, Homero Batista Mateus da. Comentários à reforma trabalhista: análise da lei 14.467/2017: artigo por artigo. São Paulo: Revista dos Tribunais, 2017.

MANZANO, Marcelo; CALDEIRA, Christian Duarte. Dinâmica recente do mercado de trabalho brasileiro ainda nos marcos da CLT. In: KREIN, J.D.; GIMENEZ, D. M.; SANTOS, A.L. Dimensões críticas da reforma trabalhista no Brasil. Campinas, São Paulo: Curt Nimuendaju, 2018.

MINISTÉRIO PÚBLICO DO TRABALHO. Nota técnica n. 8. 28 de junho de 2017. Disponível em: http://portal.mpt.mp.br/wps/wcm/connect/portal_mpt/204a16b70bca-409d-a7fd- . Acesso em: 19 ago. 2017.

MORAES, Camila Miranda de; GAIA, Fausto Siqueira. Reforma trabalhista e o conceito de sistema jurídico. Revista Jurídica Cesumar - Mestrado, Maringá (PR), v. 18, n. 1, p. 35-64, janeiro/abril 2018. Disponível em: http://periodicos.unicesumar.edu.br/ index.php/revjuridica/article/view/6212/3178. Acesso em: 9 julho 2018.

PINTO, Airton Pereira. Direito do Trabalho, Direitos Humanos sociais e a Constituição Federal. São Paulo: LTr, 2006.

SOUTO MAIOR, Jorge Luiz de. Do direito à desconexão do trabalho. 2003. Disponível em: http://www.jorgesoutomaior.com/uploads/5/3/9/1/53916439/do direito_\%C3\%A0_desconex\%C3\%A3o_do_trabalho.pdf. Acesso em: 19 ago. 2017. 